\title{
Testing for Weak-Form Market Efficiency in the Botswana Stock Market
}

\author{
Mphoeng Mphoeng \\ University of Botswana \\ Kevin Moalosi \\ University of Botswana
}

\begin{abstract}
The theory of the Efficient Market Hypothesis (EMH) has been debated extensively. In this study the runs test was employed on the Botswana Stock Exchange daily Domestic Companies and Foreign Companies indices to test whether the Botswana stock market follows the random walk process and subsequently determine weak-form market efficiency. The results of the runs test showed that the indices do not follow the random walk process. As a result the Botswana stock market is determined to be weak-form market inefficient and rejects the efficient market hypothesis accordingly.
\end{abstract}

\section{INTRODUCTION}

The efficient market hypothesis is a crucial hypothesis in the field of finance. It states that an efficient market is a market in which stock prices fully reflect available information, and that all new information is manifested in the prices (Fama, 1970). Under the hypothesis the future value of a stock cannot be predicted based on its past information. Therefore, the more efficient a stock market is, the more unpredictable future stock prices become, and the unpredictability of stock prices is known as the random walk process (Obayagbona \& Igbinosa, 2015). There is evidence that stock markets that adhere to the efficient market hypothesis tend to be those in economies with developed financial sectors, hence found mainly in developed countries (Smith, Jefferis, \& Ryoo, 2002). Consequently, analysts are able to determine the degree of institutional maturity of a country's financial sector through ascertaining the state of market efficiency in its capital markets.

Determining the presence and degree of stock market efficiency has an impact on the behaviour of stock market participants. For instance financial analysts seeking to make positive returns have to use investment techniques that correspond with the level of market efficiency found within that particular stock market, and, the failure to do so would result in low returns or losses (Bodie, Kane, \& Marcus, 2013).

The results of empirical research on market efficiency across different countries reveal mixed findings (Obayagbona \& Igbinosa, 2015) and this may be due to the specific characteristics each country exhibits. One particular characteristic noted is the level of development in the country's financial sector, or in other words, whether the markets are developed or still emerging.

In emerging markets the movement of stock prices are expected to strongly reject the random walk process due to the underdevelopment of these markets (Hiremath, 2014). For instance in the African markets Smith, Jefferis \& Ryoo (2002) examined the market efficiency of 8 emerging stock markets including Botswana, Egypt, Kenya, Mauritius, Morocco, Nigeria, South Africa, and Zimbabwe, through testing whether the countries' stock market price indices adhere to the random walk. This study finds that amongst the 8 countries, 7 rejected the 
random walk process, hence only the South African stock market was found to be weak form efficient.

In Botswana, the Botswana Stock Exchange (BSE) is the country's national stock exchange that operates and regulates the stock and fixed interest markets (Botswana Stock Exchange, 2017). Additionally the BSE, like all stock exchanges, acts as a platform in which the government and private sector obtain funding through raising capital (Botswana Stock Exchange, 2017) and continues to help investors and local businesses to date.

There is a low amount of empirical research concerning testing the Botswana stock market for weak form market efficiency, as compared to the global markets. Furthermore the most recent study was performed 4 years ago (Radikoko, 2014), though a number of changes have occurred in Botswana's capital markets since and has yet to be accounted for.

The purpose of this study therefore is to test whether the Botswana stock market still follows the random walk model and subsequently determine if the market is weak-form efficient.

\section{REVIEW OF RELATED LITERATURE}

\section{Efficient Market Hypothesis and the Random Walk Model}

The theory of the Efficient Market Hypothesis (EMH) has been debated extensively, with many researchers using random walk characteristics to test for market efficiency. The EMH was formalised by Fama (1970) and defines an efficient market as a market in which stock prices fully reflect available information, and that all new information is manifested in the prices. Fama (1970) divides market efficiency into 3 types according to the level of stock market information publicised; the weak-form, semi-strong form and the strong form efficient.

Under the weak-form market efficient stock prices reflect all available information that can be obtained from market trading data, that is, past stock prices and trading volumes (Metghalchi, Chang, \& Marcucci, 2008). Additionally the semi-strong form market efficiency stock prices reflect all publicly available information such as company annual reports and past market information, thus this form encompasses the weak-form EMH. Finally the strong form EMH stock prices reflect all public and private information, and this form contains the semi-strong and weak-form EMH. As private information is also made known, insider trading cannot occur in a strong form efficient market (Metghalchi, Chang, \& Marcucci, 2008).

Although the efficient market hypothesis is widely accepted, some experts disagree with its key assumptions. For example Hiremath (2014) argues that the EMH cannot be viewed as fully accurate because of its assumption that market participants always arrive at a rational expectation forecast, though studies have proven that that is not always the case. Also, further studies have shown that the role of psychological elements in determining stock prices play a role in predicting future prices (Hiremath, 2014), hence the movement of stock returns may be predictable to some extent.

In general researchers can determine weak-form market efficiency of a stock market through testing whether the market follows the random walk process (Okpara, 2010). The random walk process is a concept of the Random Walk Hypothesis (RWH), which according to Obayagbona and Igbinosa (2015) states that stock price fluctuations do not follow any trend and, because of this trend irregularity, "past price movements cannot be used to predict future price movements." Chang, Lima \& Tabak (2004) agree with this definition and suggest that the random walk process has important implications for asset price modelling, especially for market participants who base their investment decisions on patterns in stock prices. 


\section{Emerging Markets and Market Efficiency}

Smith, Jefferis \& Ryoo (2002) suggest that emerging markets are inefficient due to several reasons. These include the level of liquidity, the size of the stock exchanges in terms of the sales of capital stock, and the institutional maturity in that particular country.

A market is considered to be liquid if its securities are traded in with relative ease at turnovers relative to its size, and it is unlikely that a market with low levels of turnovers would have a "sufficiently active price formation process for the market to follow a random walk" (Smith, Jefferis, \& Ryoo, 2002). According to the study, the reason for this may be that due to the low levels of turnover, little to no trades would occur from one period to the next hence the security's price would remain unchanged.

In Botswana there have been few released articles concerning testing the Botswana stock market for weak form market efficiency, compared to the global markets. Mollah (2006) used the daily price indices from the Domestic Companies Index (DCI) for the period 1989-2005, as it was the only stock price index in Botswana during the period. The study used the Kolmogrov-Smirnov Goodness of Fit test, Runs test, auto-correlation test, auto-regressive model, and the Auto Regressive Integrated Moving Average (ARIMA) model to determine weak-form market efficiency.

Radikoko (2014) on the other hand used the daily and monthly returns of the Domestic Companies Index (DCI) for the period 1989-2013 and the Foreign Companies Index (FDI) for the period 2005-2013. Unlike the previous study Radikoko (2014) was able to use data from the FDI as it had been established at the time the study was performed. Furthermore Radikoko (2014) employed the auto-correlation test, the Augmented Dickey Fuller test, runs test and the Rescaled Range Analysis to test for weak-form market efficiency.

In comparison to the previous papers, this study will be the most up to date test for market efficiency in Botswana as the last study was performed four years ago by Radikoko (2014). Additionally, the study will employ the runs test alone unlike Mollah (2006) and Radikoko (2014). The results of the runs test will be easily comparable to that of previous studies as it was used by both Mollah (2006) and Radikoko (2014).

Based on the above literature the below hypothesis were formulated

H1: Botswana's stock market does not follow a random walk.

H2: Botswana's stock market is weak form inefficient.

The study will test for market efficiency by determining the presence of random walk process empirically through employing the runs test. Daily stock market indices of the DCI as well as the FDI will be used as a source of data.

\section{METHODOLOGY}

The runs test will be employed to test whether Botswana's stock market follows the random walk process, in order to determine its market efficiency. As a result, the runs test will be used to examine the daily stock market indices of the Botswana Stock Exchange (BSE). A sample size of 10 years will be used, as a larger sample may reduce the effects of anomalies, which can distort the results of the runs test. Secondary data will be used for data collection. The secondary data will be comprised of the daily stock price indices of the Domestic Companies Index (DCI) and Foreign Companies Index (FCI) as they are the only stock indices available in 
the stock exchange. The raw data from the DCI and FCI stock price indices will both be obtained for the period 2007-2017 accordingly.

There are various methods available to verify weak-form market efficiency in stock markets, and the runs test is a common method of doing so (Khan, Ikram, \& Mehtab, 2011). The runs test, tests for the random walk of stock prices. The more efficient a market is, the more random and unpredictable the market stock prices would be and as a result the most efficient markets possess completely random future prices independent on the past prices (Khadoker, Siddik, \& Azam, 2011)

As such, the runs test determines that level of randomness in the stock prices. Islam, Watanapalachaikul \& Clark (2005) define a run as;

...The repeated occurrence of the same value or category of a variable. It is indexed by two parameters, which are the type of the run and the length. Stock price runs can be positive (+), negative (-), or have no change. The length is how often a run type occurs in succession...

They further go on to explain that under the null hypothesis successive outcomes are independent hence lack serial dependence (Islam, Watanapalachaikul, \& Clark, 2005).

According to the runs test employed by Khan, Ikram, and Mehtab (2011) the total expected number of runs is distributed as normal with the following mean:

$$
\bar{R}=\frac{N\left(n_{1} n_{2)}\right)}{n_{1}+n_{2)}}+1
$$

Where;

is the mean or average number of expected runs

is the number of positive $(+)$ runs observed.

is the number of negative $(-)$ runs observed.

With the following standard deviation:

$$
\sigma_{R}=\left[\frac{2\left(n_{1} n_{2}\right)\left(2\left(n_{1} n_{2)}-n_{1}-n_{1}\right)\right.}{\left(n_{1} n_{2)}\right)^{2}\left(n_{1}+n_{2}-1\right)}\right]^{\frac{1}{2}}
$$

Where

is the standard deviation of the number of runs

is the number of positive $(+)$ runs observed.

is the number of negative $(-)$ runs observed.

The test for serial dependence is carried out by comparing the actual number of runs, $a_{r}$ in the price series to the expected number $\mu$. If the expected number of runs is significantly different from the actual number runs the null hypothesis of random movement in stock prices is rejected (Mollah, 2006).

To test for that significant difference the runs test result is converted into a $Z$ statistic, which is a measurement of the distance of a value from the standard deviation and Khan, Ikram and Mehtab (2011) calculate it as: 


$$
Z=\frac{R-\bar{R}}{\sigma_{R}}
$$

Where;

$Z$ - The $Z$ statistic

$R$ - The total observed number of runs that is:

$$
R=n_{1}+n_{2}
$$

$\bar{R}$ - The mean expected number of runs

Under the Runs Test the hypotheses according to Mollah (2006) are as follows:

The null hypothesis $\left(\mathrm{H}_{0}\right)$ : The observed indices are random series.

The alternative hypothesis $\left(\mathrm{H}_{1}\right)$ : The observed indices are not random series

If the $Z$ statistic is greater than or equal to \pm 1.96 then the runs test is rejected (Khan, Ikram, \& Mehtab, 2011).

The runs test will be employed in the aforementioned method for the daily stock price indices in the DCI, FCI and ACI. The results of the runs test will then be used to test the BSE stock price indices for random walk process and subsequently determine whether the Botswana stock market is weak-form market efficient.

Additionally, if there are any gaps in the series of data, they will be filled by the average of the two values between the gaps, instead of placing a zero value. This will be done to prevent the gaps or zero values from distorting the trend obtained from the results.

\section{FINDINGS AND DISCUSSIONS}

The runs test was applied on the two BSE daily stock prices indices, the Domestic Companies Index (DCI) and the Foreign Companies Index (FCI), and the results are presented in Table 1 (Source of data for Table 1 can be found in Appendix A).

Table 1: Results of Runs Test of BSE daily DCI and FCI for the period 2007-2017

\begin{tabular}{|l|l|l|}
\hline Description & Domestic Companies Index & Foreign Companies Index \\
\hline Number of observations & 2733 & 2733 \\
\hline Number of positive runs & 1524 & 1429 \\
\hline Number of negative runs & 1209 & 1304 \\
\hline Total observed runs & 916 & 551 \\
\hline Expected number of runs & 1349 & 1365 \\
\hline Standard deviation & 25.787 & 26.080 \\
\hline Z-statistic & -16.805 & -31.198 \\
\hline
\end{tabular}

The calculations for the number of positive and negative runs, total observed runs, expected runs and standard deviation are presented in the table for both the DCI and FCI indices.

The Z-statistics were also computed to determine whether the expected number of runs were significantly different from the actual number of runs observed. If the $\mathrm{Z}$ statistic for either index is greater than or equal to \pm 1.96 then the runs test is rejected (Khan, Ikram, \& Mehtab, 2011).

Under the Domestic Companies Index the actual observed number of runs was 916 whilst the expected number of runs was 1349. The $\mathrm{Z}$ statistic between the observed number of runs and 
expected number of runs was determined to be -16.805 . The $\mathrm{Z}$ value of the $\mathrm{DCI}$ is 14.845 greater than the critical $\mathrm{Z}$ value \pm 1.96 , thus the runs test is rejected. As a result, the BSE DCI does not follow the random walk process as it shows serial dependence.

Additionally, under the Foreign Companies Index the actual observed number of runs was 551 while the expected number of runs was 1365. The FCI Z-value was found to be -31.198 , which was almost twice as large as that of the DCI. Similar to the DCI, the Z value is greater than the critical Z-value \pm 1.96 , thus the FCI rejects the runs test. Consequently the BSE FCI does not adhere to the random walk hypothesis as the index reveals a predictable trend based on its past prices.

The runs test was rejected by both the BSE DCI and FCI hence reveals that the indices do not follow the random walk process. As a result the Botswana stock market is determined to be weak-form market inefficient and rejects the efficient market hypothesis accordingly. Furthermore the results of the runs test for the BSE DCI and FCI are similar to that of Mollah (2007) and Radikoko (2014) and both concluded that Botswana's stock market lacks weakform market efficiency.

Although the findings computed from the runs test have determined that the Botswana stock market rejects the random walk hypothesis, the test alone is not adequate enough to make an accurate decision in determining market efficiency. Testing the random walk process in stock market indices is a complex exercise that requires the use of various techniques to draw accurate empirical evidence. In this research paper however, only one analytical technique was employed and hence the level of accuracy of the results reduced accordingly.

Furthermore the number of stock market indices is few in Botswana as compared to countries with developed markets. Therefore it will not be possible to draw a more valid conclusion as it is with other countries.

\section{CONCLUSION AND RECOMMENDATIONS}

The theory of the Efficient Market Hypothesis (EMH) has been debated numerously, and many researchers use random walk characteristics to test for market efficiency. In this study the runs test was employed on the BSE daily DCI and FCI indices to test whether the Botswana stock market follows the random walk process and subsequently determine weak-form market efficiency. The results of the runs test showed that the indices do not follow the random walk process. As a result the Botswana stock market is determined to be weak-form market inefficient and rejects the efficient market hypothesis accordingly.

According to Chang, Lima and Tabak (2004) a country's stock market may be weak-form inefficient for a number of reasons. One particular reason may be the level of development in the country's financial sector. In emerging markets the movement of stock prices are expected to strongly reject the random walk process due to the underdevelopment of these markets (Hiremath, 2014). The results of the research are consistent with Hiremath's findings since Botswana is still a developing country.

On the other hand Smith, Jefferis \& Ryoo (2002) argue that the level of liquidity in the stock market has an impact on a country's market efficiency. Low levels of liquidity are attributed to low levels of turnover, that little to no trades would occur from one period to the next, thus the stock prices would remain unchanged. Therefore according to the results of the research the Botswana stock market's lack of weak-form market efficiency may be due to the periodical low levels of stock turnovers. 
In light of the above conclusions we have made the below recommendations:

a) Continued research is needed on various aspects of the stock market to try and improve knowledge in a bid to improve efficiencies.

b) More development efforts are required in order to increase liquidity of the stock market, which will in turn increase efficiency. Different investor types need to be enticed to participate and develop the capital markets in Botswana.

\section{BIBLIOGRAPHY}

Bodie, Z., Kane, A., \& Marcus, A. J. (2013). Essentials of Investments (9th ed.). New York: McGraw-Hill Irwin.

Botswana Stock Exchange. (2017). BSE - Role in Botswana. Retrieved from Botswana Stock Exchange:

https://www.bse.co.bw/abt_us/role_in_botswana.php

Chang, E. J., Lima, E. J., \& Tabak, B. (2004). Testing for predictability in emerging equity markets. Emerging Markets Review, 5, 295-316.

Fama, E. F. (1970). Efficient capital markets: a review of theory and empirical work. Journal of Finance, 25(2), 383-417.

Hiremath, G. (2014). Random Walk Characteristics of Stock Returns. In G. Hiremath, Indian Stock Markets (pp. 1839). Springer.

Islam, M., Watanapalachaikul, S., \& Clark, C. (2005). Are Emerging Financial Markets Efficient?: Some Evidence from the Models of the Thai Stock Market. Victoria University.

Khadoker, S., Siddik, N., \& Azam. (2011). Tests of weak-form market efficiency of Dhaka Stock Exchange. Interdisciplinary Journal of Research in Business, 1(9), 47-60.

Khan, A., Ikram, S., \& Mehtab, M. (2011). Testing weak form market efficiency of Indian capital market: A case of national stock exchange (NSE) and Bombay stock echange (BSE). African Journal of Marketing Management, 3(6), 115-127.

Lima, E. J., \& Tabak, B. M. (2004). Tests of the random walk hypothesis for equity markets: evidence from China, Hong-Kong and Singapore. Applied Economics Letters, 11, 255-258.

Metghalchi, M., Chang, J., \& Marcucci, J. (2008). Is the Swedish stock market efficient? Evidence from some simple trading rules. International Review of Financial Analysis, 475-490.

Mollah, A. S. (2006). Testing Weak-Form Market Efficiency in Emerging Market: Evidence From Botswana Stock Exchange. University of Botswana, Department of Accounting \& Finance, Gaborone.

Obayagbona, J., \& Igbinosa, S. O. (2015). Test of random walk hypothesis in the Nigerian stock market. Current Research Journal of Social Sciences, 7(2), 27-36.

Okpara, G. (2010). Stock market prices and the random walk hypothesis: Further evidence from Nigeria. Journal of Economics and International Finance, 2(3), 049-057.

Radikoko, I. (2014). Testing the random walk (Rw) behaviour of Botswana's equity returns. Journal of Business Theory and Practise, 2(1), 84-99.

Smith, G., Jefferis, K., \& Ryoo, H. (2002). African stock markets: multiple variance ratio tests of random walks. Applied Financial Economics, 12, 475-484. 